\title{
Mika Haka Foundation: Performing Empowerment
}

\author{
MIKA, PARE KEIHA, SHARON MAZER
}

\begin{abstract}
Mika is famous for his boundary-bursting performances, and as a lifestyle liberationist who has used his brand more to create social change than to campaign for an Oscar. Working with young people, including those who might be termed 'at risk', has always been at his core, even if he's kept that kind of work predominantly 'in the closet'. He auditions them, trains them up, enforces health literacy, financial literacy and political and cultural awareness, whilst teaching them how to sing, dance, act and manage themselves onstage and off. He transforms these young people into 'emerging leaders', invests them with social capital and encourages them to perform their own empowerment. He's been doing this a very long time, in fact: from the early 1980s in Christchurch with the Coloured Crew Lockers to his creation of Torotoro in the early 2000s, and now under the auspices of the Mika Haka Foundation. The images here offer a glimpse into Mika's current collaborations, which will be the topic of a conversation between Mika and Pare Keiha, the Chair of the Mika Haka Foundation Trust Board, as moderated by Sharon Mazer at the Ka Haka Empowering Performance: Māori and Indigenous Performance Studies Symposium. We ask: how does educating young people as entrepreneurial entertainers potentially lead to their emancipation?
\end{abstract}




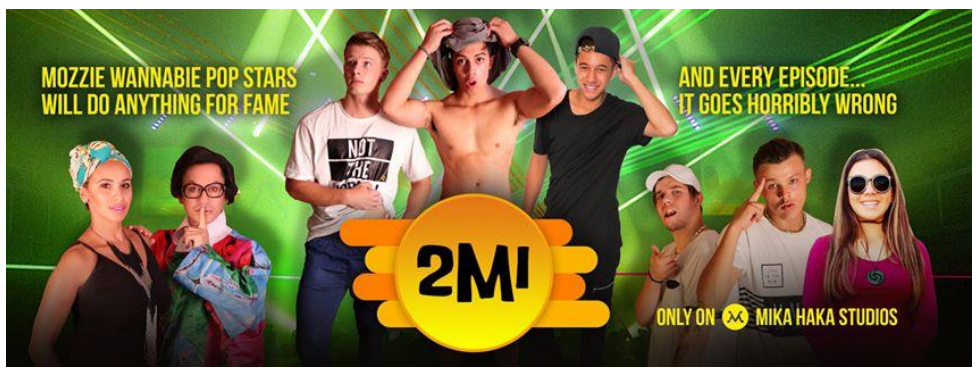

Photo 1: 2MI Web-Series - Megan Alatini, Mika Haka, Rabbit Proof Boys, Stuck On 24/7 \& Te Amo. Photo by: Jay Tewake

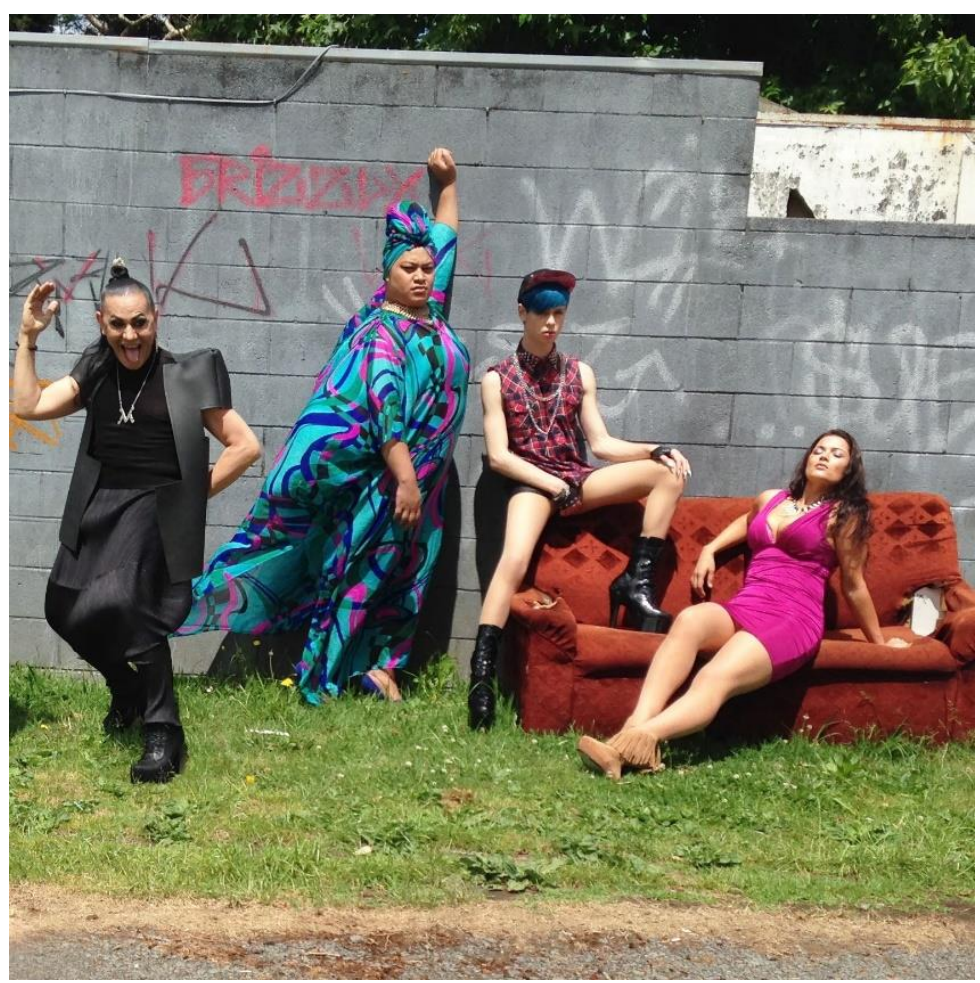

Photo 2: Metro Shoot - Mika Haka, Ashley Tonga, Zakk d'Larte, Hannah Martin. Photo by: Metro Magazine

Te Kaharoa, Special Edition, Ka Haka - Empowering Performance: Māori and Indigenous Performance Studies Symposium, vol. 9, 2016, 


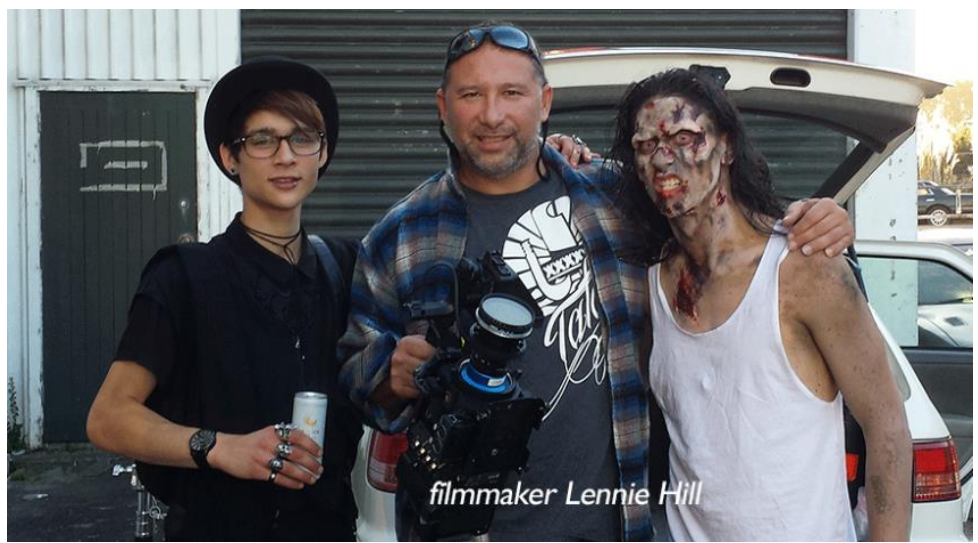

Photo 3: Coffee Music Video - Ryan Turner, Lennie Hill, Jay Tewake. Photo by: Jay Tewake

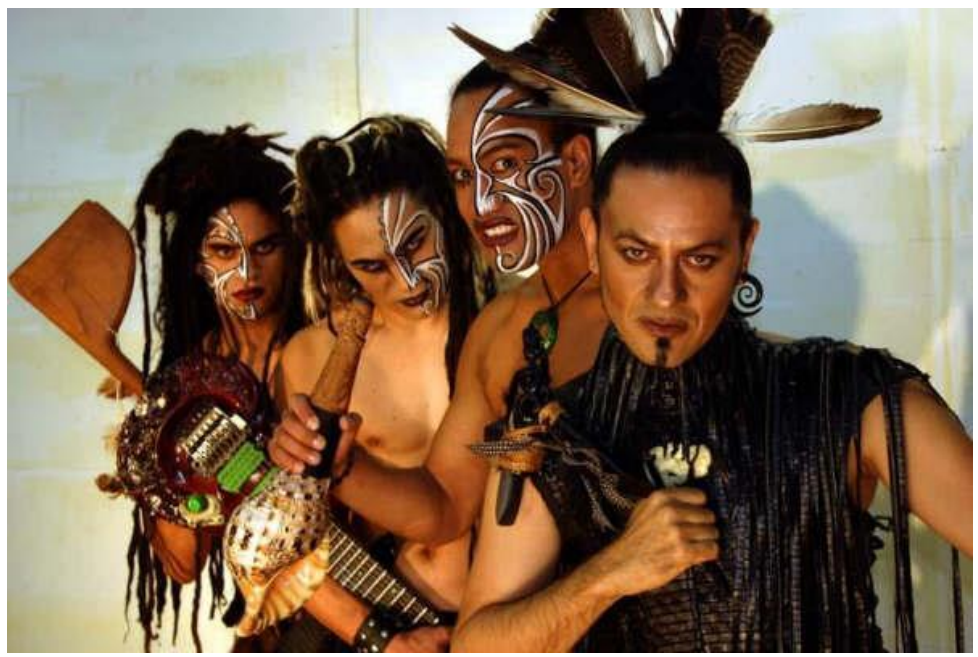

Photo 4: Plastic Maori - Mokoera Te Amo, Kingi Tuu Taniwha, Taupuhi Toki \& Mika Haka. Photo by: Darcy Gladwin

Te Kaharoa, Special Edition, Ka Haka - Empowering Performance: Māori and Indigenous Performance Studies Symposium, vol. 9, 2016, 
Mika has starred as the opening act for Grace Jones in New York City, he has entertained His Royal Highness Prince Charles at the Palace of Holyroodhouse, and his performance in the Oscar-winning film The Piano shocked audiences around the globe. In an era of repetitive pop culture, Mika is a rare commodity - a truly original New Zealand Māori artist - and an entertainer with three decades of innovative work spanning stage, film, television, fashion and music. With a large international fan base, Mika is in high demand to perform in Aotearoa and abroad, touring his critically acclaimed live shows to seven Edinburgh Festivals, and to New York, London, Tokyo and beyond. He has recorded seven albums in te reo Māori and English and is an APRA Maioha Award nominee. He has appeared in over twenty television series and specials - from TVNZ classics Shark in the Park and Shortland Street, to his own Qantas Award nominated Mika Haka Kids and Ka Life for Māori Television. Throughout his broadly rewarding career, Mika has inspired and educated new generations of Māori and Pacific Island artists and performers - a multi-talented 'tribe' that includes actors, dancers, singers and musicians, visual artists and fashion designers. His artistic achievements stand proudly alongside his philanthropic work as kaitiaki of the Mika Haka Foundation, a charity organisation committed to keeping young New Zealanders active and healthy through physical culture and the performing arts.

Pare Areta Keiha (QSO, MSC, PhD, MBA, MComLaw, FRSA, MInstD, MRSNZ) is Pro Vice Chancellor for Māori Advancement, Pro Vice Chancellor for Learning and Teaching and Dean of Te Ara Poutama, the Faculty of Māori and Indigenous Development, at Auckland University of Technology. He has an extensive background in the governance of public and private companies, has supported a number of Auckland based arts and culture charities and is currently chair of the Mika Haka Foundation. He was honoured in the 2008 New Year's Honours List when he was made a Companion of the Queen's Service 
Order (QSO) for his services to business, education and Māori. $\mathrm{He}$ has contributed to nationally significant research agendas including as a member of the 2002 PBRF Working Group and the second PBRF Sector Reference Group. He was a member of the first three CoRE Fund committees of the Royal Society of New Zealand, responsible for establishing the New Zealand Centres of Research Excellence. He is currently a member of the board of Ngā Pae o te Māramatanga, the Māori CoRE hosted by Auckland University, and of the FIET board hosted by Massey University. His present academic pursuits include mobile and digitally based solutions for enhanced teaching and learning, corporate governance, competition law and policy, intellectual property law, and Māori and Pacific development. His tribal affiliations lie with the principle tribes of Turanga (Gisborne), specifically Te Whānau-a-Taupara o T'Aitanga-a-Māhaki, and Rongowhakaata, and he is a trustee of the Te Whānau-aTaupara Trust Board.

Sharon Mazer is Associate Professor of Theatre and Performance Studies at Auckland University of Technology. Perhaps best known for her work on popular performance, including her book Professional Wrestling: Sport and Spectacle (Mississippi 1998), her current research focuses on diverse aspects of theatre and performance in Aotearoa New Zealand. Forthcoming: The Intricate Art of Actually Caring . . . and other New Zealand Plays (Seagull Books 2016), the first critically framed anthology to bring together plays by Māori, Samoan and Pākehā writers; and Mātiro: Look Inside, the life and times of gay Māori performance artist, Mika. 